\title{
Reoperation for enlargement of the distal aorta after initial surgery for acute type A aortic dissection
}

\author{
Naoyuki Kimura, MD, PhD, Satoshi Itoh, MD, PhD, Koichi Yuri, MD, Koichi Adachi, MD, \\ Harunobu Matsumoto, MD, PhD, Atsushi Yamaguchi, MD, PhD, and Hideo Adachi, MD, PhD
}

Objective: We investigated the long-term outcomes of repair for acute type A aortic dissection on the basis of false lumen status and assessed treatment modalities for the enlarged downstream aorta.

Methods: Between January 1990 and March 2013, 534 patients underwent surgery for acute type A aortic dissection. In-hospital mortality was 9.3\% (50/534), and follow-up was 98\% (472/484). Of the 472 hospital survivors, $451(96 \%)$ underwent contrast-enhanced computed tomography within 1 month of surgery. Risk-adjusted survival and distal aortic events were investigated in these 451 patients. Surgical outcomes of distal reoperations were assessed in 37 patients.

Results: Postoperative false lumen patency was $62 \%$ (280/451). Eighteen patients died of aortic rupture, 17 $(94 \%)$ with a patent false lumen. A patent false lumen decreased survival (hazard ratio [HR], 1.70; $P=.012)$ and increased distal aortic events (HR, 4.11; $P=.001)$. Other predictors identified were age (HR, $1.07 ; P<.001)$ and male sex (HR, 1.89; $P=.002)$ for late mortality, and Marfan syndrome (HR, 6.6; $P<.001)$, distal aortic diameter greater than $45 \mathrm{~mm}(\mathrm{HR}, 4.4 ; P<.001)$, and nonresection of the primary entry (HR, 2.3; $P=.005)$ for distal aortic events. Distal reoperations comprised open repair of the arch $(\mathrm{n}=13)$, descending aorta $(\mathrm{n}=16)$, or thoracoabdominal aorta $(\mathrm{n}=7)$ or thoracic endovascular aortic repair $(\mathrm{n}=7)$, with no in-hospital death or paraplegia. Although thoracic endovascular aortic repair yielded false lumen thrombosis around the stent graft in $80 \%$ of patients (4/5), complete false lumen thrombosis was achieved in $20 \%(1 / 5)$.

Conclusions: False lumen patency influences the late outcomes of acute type A aortic dissection repair. Outcomes of distal reoperation were acceptable; thus, careful follow-up and timely reoperation may improve the late outcomes. (J Thorac Cardiovasc Surg 2015;149:S91-8)

\section{Supplemental material is available online.}

Hybrid aortic arch repair, such as aortic arch replacement with frozen elephant trunk (FET) repair, has been reported to improve the long-term outcomes of acute type A aortic dissection (ATAAD). ${ }^{1-5}$ However, ascending aorta or hemiarch replacement remains the most commonly used surgical procedure for ATAAD. Investigators representing the German Registry for Acute Aortic Dissection Type A

\footnotetext{
From the Department of Cardiovascular Surgery, Saitama Medical Center, Jichi Medical University, Saitama, Japan.

Disclosures: Authors have nothing to disclose with regard to commercial support. Drs N.K. and S.I. contributed equally to this study.

Read at The American Association for Thoracic Surgery Aortic Symposium, New York, New York, April 24-25, 2014.

Received for publication April 22, 2014; revisions received Aug 2, 2014; accepted for publication Aug 7, 2014; available ahead of print Sept 12, 2014

Address for reprints: Naoyuki Kimura, MD, PhD, Department of Cardiovascular Surgery, Saitama Medical Center, Jichi Medical University, 1-847 Amanumacho, Omiya, Saitama 330-0834, Japan (E-mail: kimura-n@omiya.jichi.ac.jp). $0022-5223 / \$ 36.00$

Copyright $(2015$ by The American Association for Thoracic Surgery http://dx.doi.org/10.1016/j.jtcvs.2014.08.008
}

reported that $68.9 \%$ of patients $(1474 / 2137)$ with ATAAD were treated with ascending aorta replacement with or without hemiarch replacement. ${ }^{6}$ Ascending aorta replacement is associated with a high incidence of residual patent false lumen $(\mathrm{FL})^{7,8} \mathrm{~A}$ patent $\mathrm{FL}$ in the downstream aorta promotes enlargement of the downstream aorta and increases the risk of aortic rupture or reoperation..$^{9-14}$ Therefore, management of the enlarged downstream aorta is a problem that aortic surgeons face and need to address promptly.

We perform mainly ascending aorta or hemiarch replacement in patients with ATAAD. In 2008, we reported the long-term outcomes of ATAAD, with 5-year survival of $79.5 \%$ and 8 distal reoperations for a total of 243 patients who underwent surgery between 1997 and 2006. ${ }^{15}$ However, the number of patients who required distal reoperation increased afterward. In the present study, we investigated the long-term outcomes of initial surgery for ATAAD in relation to FL status and assessed the outcomes of reoperation for enlargement of the downstream aorta.

\section{METHODS}

\section{Study Patients}

Between January 1990 and March 2013, 534 consecutive patients underwent surgery for ATAAD at Jichi Medical University, Saitama 


$$
\begin{aligned}
& \text { Abbreviations and Acronyms } \\
& \begin{aligned}
\text { ATAAD } & =\text { acute type A aortic dissection } \\
\text { CPB } & =\text { cardiopulmonary bypass } \\
\text { CT } & =\text { computed tomography } \\
\text { FET } & =\text { frozen elephant trunk } \\
\text { FL } & =\text { false lumen } \\
\text { HR } & =\text { hazard ratio } \\
\text { TEVAR } & =\text { thoracic endovascular aortic repair }
\end{aligned}
\end{aligned}
$$

Medical Center, Saitama, Japan. In-hospital mortality after surgery for ATAAD was 9.3\% (50/534); 484 patients survived. Follow-up information, including death or survival, general health conditions, cause of death, and cardiac or aortic events, was obtained for 472 patients (follow-up rate, $98 \%$, follow-up interval, $6.8 \pm 4.9$ years) via outpatient clinic records or written or telephone contact. These 472 patients comprised the study group. Patients' clinical charts were retrospectively reviewed. The ethics committee of Jichi Medical University Saitama Medical Center granted approval for the study (Reg. No. 2014-11), and the need for individual informed consent was waived. The characteristics of the 472 study patients are shown in Table 1.

\section{False Lumen Patency in the Downstream Aorta}

Of the 472 patients, 451 (96\%) underwent contrast-enhanced computed tomography (CT) within 1 month of surgery before hospital discharge. The remaining 21 patients did not undergo contrast-enhanced CT because of renal failure, allergy to contrast medium, or refusal of the examination. FL status in the downstream aorta was assessed in patients who did undergo contrast-enhanced CT. We defined a patent FL as one that was enhanced anywhere in the downstream aorta during arterial- and venous-phase CT. ${ }^{15}$ An FL was considered patent if partial thrombosis was seen, and FL disappearance was taken as complete FL thrombosis. For patients who did not undergo venous-phase CT, patency of the FL was judged on the basis of early-phase images. ${ }^{15}$

\section{Surgical Procedures}

Initial surgery for acute type A aortic dissection. The surgical techniques have been reported in detail. ${ }^{15,16}$ Briefly, between 1991 and 1996, ringed intraluminal graft insertion was performed in 15 patients. For the remaining 457 patients, we followed the tear-oriented approach to ATAAD, and ascending aorta or hemiarch replacement was performed with open distal anastomosis during deep hypothermic circulatory arrest. Total or partial (reconstruction of 1 or 2 branches) arch replacement with selective antegrade cerebral perfusion was performed in patients whose tear was located in or extended into the aortic arch. When the entry site could not be identified or was identified in the descending thoracic aorta, the ascending aorta was replaced. The replacement technique included the interposition of a single-branch or 4-branch graft with polytetrafluoroethylene felt reinforcement of the aortic stumps. Gelatin-resorcinol-formaldehyde glue was not used. Aortic root replacement with a composite prosthesis was performed according to the modified Bentall procedure in patients with dilation of the aortic root or an aortic root damaged by the entry tear.

Reoperation for enlargement of the downstream aorta. Distal reoperation was performed for patients with an aortic diameter of $55 \mathrm{~mm}$ or more, rapid aortic growth $(10 \mathrm{~mm} / \mathrm{y})$, or rupture or impending rupture presenting as chest pain. Reoperation procedures were determined by taking into account the anatomic location of the diseased aorta, patient's age, comorbidity, and general health conditions. Our surgical strategy is shown in Figure 1. Open aortic repair remains the first-line therapy for enlargement of the downstream aorta regardless of the anatomic location of the aneurysm. However, thoracic endovascular aortic repair (TEVAR) has been used for patients with enlargement of the descending thoracic aorta since April 2011. Elderly patients or unstable patients with impending rupture have been treated with TEVAR if the intimal tear is expected to be covered with a stent graft.

Aortic arch reoperation. Median re-sternotomy was performed in 10 of 13 patients $(77 \%)$ who underwent aortic arch replacement; the remaining 3 patients underwent left anterior thoracotomy. Arterial cannulation was done via the femoral artery $(\mathrm{n}=5)$, femoral artery and axillary artery $(\mathrm{n}=5)$, axillary artery $(\mathrm{n}=1)$, or transplanted graft $(\mathrm{n}=2)$. After establishment of cardiopulmonary bypass (CPB), patients were cooled to $20^{\circ} \mathrm{C}$ to $25^{\circ} \mathrm{C}$ nasopharynx temperature. After aortic crossclamping, myocardial protection was achieved with antegrade or retrograde cardioplegia infusion. Selective antegrade cerebral perfusion was used for cerebral protection. The diseased aorta was resected, and open distal anastomosis was performed. Proximal anastomosis was performed during rewarming. Cerebral vessels were reconstructed separately, and the anastomoses were performed after declamping of the aorta.

Descending thoracic or thoracoabdominal aorta replacement. Of the 23 patients who underwent descending thoracic or thoracoabdominal aorta replacement, 7 underwent insertion of a cerebrospinal fluid drainage tube 1 day before surgery. Left anterolateral thoracotomy, posterolateral thoracotomy, or thoracoabdominal incision was selected according to the extent of the diseased aorta and length of the graft Arterial cannulation sites included the femoral artery $(n=8)$ and femoral artery plus axillary artery $(n=15)$. Total CPB was used for most patients, with cooling to $17^{\circ} \mathrm{C}$ to $22^{\circ} \mathrm{C}$ nasopharyngeal temperature. Open proximal anastomosis was performed during deep hypothermic circulatory arrest. Distal anastomosis was performed by an open or clamp method, according to the extent of repair and the surgeon's preference. The diseased aorta was resected and replaced with a single-branch or 4-branch graft. After proximal anastomosis, perfusion to the upper body was resumed via a side branch of the graft or axillary artery. The intercostal arteries located between the Th7 and L1 levels were reimplanted separately or by the island technique. In cases in which the visceral abdominal aorta was enlarged, the visceral and renal arteries were perfused by means of balloon catheters. The visceral and renal arteries were reimplanted separately or by the island technique.

Endovascular treatment. Between March 2009 and May 2013, 123 TEVAR procedures were performed at the Saitama Medical Center. Eight of these were for enlargement of the downstream aorta after ATAAD repair ( 1 of the 8 patients underwent the initial surgery at a different hospital). The site of the entry tear and the extent of dissection were determined on 0.5 - to 1-mm preoperative CT slices, including arterial- and venous-phase images. Three types of nonfenestrated thoracic stent-graft, including the Relay (Bolton Medical SL, Barcelona, Spain), GORE TAG (WL Gore \& Associates, Inc, Flagstaff, Ariz), and Zenith Tx2 (Cook Medical Inc, Bloomington, Ind), and 1 fenestrated thoracic stent-graft (Najuta, Kawasumi Laboratory, Tokyo, Japan) ${ }^{17,18}$ were used. Covered length was determined intraoperatively according to the aortic pathology. Stent grafts were approximately $10 \%$ oversized relative to the diameter of the aorta immediately proximal to the dissection. Type Ia (antegrade perfusion of the FL) and type II (perfusion of the FL via the overstented left subclavian artery) endoleaks were considered major endoleaks. ${ }^{19}$ Follow-up CT was performed immediately after surgery, 3 to 4 months after surgery, and every 6 months thereafter.

\section{Statistical Analysis}

Data are presented as mean \pm standard deviation, median (interquartile range) values, or percentages, as appropriate. Patients were divided into 2 groups according to FL status: patent or thrombosed. Between-group differences in clinical and morphologic variables were analyzed by 
TABLE 1. Perioperative characteristics of hospital survivors grouped according to false lumen status

\begin{tabular}{|c|c|c|c|c|}
\hline Variables & Total $(n=472)$ & Patent FL $(n=280)$ & Thrombosed FL $(n=171)$ & $P$ value \\
\hline \multicolumn{5}{|l|}{ Background clinical characteristics } \\
\hline Age, mean $\pm \mathrm{SD}(\mathrm{y})$ & $63.5 \pm 12.2$ & $60.0 \pm 12.1$ & $68.7 \pm 10.2$ & $<.01$ \\
\hline Sex, male & $245(52 \%)$ & $162(58 \%)$ & $71(42 \%)$ & $<.01$ \\
\hline Marfan syndrome & $12(3 \%)$ & $9(3 \%)$ & $3(2 \%)$ & .52 \\
\hline Bicuspid aortic valve & $4(1 \%)$ & $2(1 \%)$ & $1(1 \%)$ & 1.0 \\
\hline Hypertension & $339(70 \%)$ & $203(73 \%)$ & $114(67 \%)$ & .18 \\
\hline Dyslipidemia & $74(16 \%)$ & $42(15 \%)$ & $32(19 \%)$ & .28 \\
\hline Diabetes mellitus & $26(6 \%)$ & $17(6 \%)$ & $9(5 \%)$ & .73 \\
\hline History of ischemic heart disease & $21(5 \%)$ & $9(3 \%)$ & $12(7 \%)$ & .063 \\
\hline History of cerebrovascular disease & $35(8 \%)$ & $16(6 \%)$ & $19(11 \%)$ & .036 \\
\hline COPD & $16(3 \%)$ & $7(3 \%)$ & $8(5 \%)$ & .21 \\
\hline Hemodialysis & $9(2 \%)$ & $3(1 \%)$ & $5(3 \%)$ & .15 \\
\hline Previous cardiac surgery & $6(1 \%)$ & $6(2 \%)$ & $0(0 \%)$ & .13 \\
\hline \multicolumn{5}{|l|}{ Dissection characteristics } \\
\hline \multicolumn{5}{|l|}{ DeBakey classification } \\
\hline Type I & $472(89 \%)$ & $276(99 \%)$ & $130(76 \%)$ & $<.01$ \\
\hline Type II & $50(11 \%)$ & $4(1 \%)$ & $41(24 \%)$ & $<.01$ \\
\hline \multicolumn{5}{|l|}{ Entry site } \\
\hline Ascending aorta & $297(63 \%)$ & $170(61 \%)$ & $113(66 \%)$ & .25 \\
\hline Aortic arch & $62(13 \%)$ & $43(15 \%)$ & $18(11 \%)$ & .15 \\
\hline Descending aorta or unknown & $112(24 \%)$ & $66(24 \%)$ & $40(23 \%)$ & .97 \\
\hline \multicolumn{5}{|l|}{ Surgical procedure } \\
\hline Intraluminal graft insertion & $15(3 \%)$ & $8(3 \%)$ & $5(3 \%)$ & .97 \\
\hline Aortic root replacement & $21(4 \%)$ & $18(6 \%)$ & $3(2 \%)$ & .040 \\
\hline CABG & $35(7 \%)$ & $19(7 \%)$ & $14(8 \%)$ & .58 \\
\hline Resection of the primary entry & $352(75 \%)$ & $210(75 \%)$ & $128(75 \%)$ & .97 \\
\hline \multicolumn{5}{|l|}{ Distal extent of resection } \\
\hline Ascending aorta or hemiarch & $391(83 \%)$ & $227(81 \%)$ & $146(85 \%)$ & .24 \\
\hline Ascending aorta + aortic arch & $66(14 \%)$ & $45(16 \%)$ & $20(12 \%)$ & .20 \\
\hline \multicolumn{5}{|l|}{ CT finding before hospital discharge } \\
\hline Distal aortic diameter $>45 \mathrm{~mm}$ & N/A & $49(18 \%)$ & $19(11 \%)$ & .069 \\
\hline Beta-blocker at hospital discharge & $276(59 \%)$ & $177(63 \%)$ & $89(52 \%)$ & .019 \\
\hline ARB at hospital discharge & $160(34 \%)$ & $107(38 \%)$ & $50(29 \%)$ & .052 \\
\hline
\end{tabular}

Number and percentage of patients are shown unless otherwise indicated. $A R B$, Angiotensin receptor blocker; $C A B G$, coronary artery bypass grafting; $C O P D$, chronic obstructive pulmonary disease; $C T$, computed tomography; $F L$, false lumen; $S D$, standard deviation; $N / A$, not applicable.

chi-square or Fisher exact test or by unpaired $t$ test or Mann-Whitney $U$ test. Forward stepwise Cox proportional hazards regression analysis was performed to identify independent predictors of late mortality and distal aortic events. In addition to the perioperative variables shown in Table 1, FL status was examined for the Cox proportional hazard modeling. Distal aortic events included sudden death, aortic rupture, re-dissection, and reoperation in the downstream aorta. All perioperative variables examined and patent FL were entered into multivariate analysis. Riskadjusted Kaplan-Meier curves based on Cox models were constructed by using SAS 9.4 (SAS Institute Inc, Cary, NC). All other statistical analyses were performed with SPSS 17.0 (SPSS Inc, Chicago, Ill). $P<.05$ was considered statistically significant.

\section{RESULTS}

\section{Long-Term Outcomes According to False Lumen Status}

Residual FL patency after surgery for ATAAD was $62.0 \%$ (280/451). Patients' perioperative characteristics are shown per group in Table 1. Patients in the patent FL group were more likely than patients in the thrombosed
FL group to be young and male. Although most DeBakey type II cases showed no FL postoperatively, a few showed a partially thrombosed FL in the aortic arch. Neither the extent of dissection of the distal aorta nor the resection of the primary entry site was associated with FL patency.

A total of 115 patients died during the mean follow-up (period of $6.8 \pm 4.8$ years). The leading cause of late mortality was malignancy $(n=26,23 \%)$, followed by heart failure $(\mathrm{n}=24,21 \%)$, aortic rupture or sudden death $(\mathrm{n}=18,16 \%)$, pneumonia $(\mathrm{n}=17,15 \%)$, cerebrovascular disease $(n=15,13 \%)$, renal failure $(n=6,5 \%)$, and other causes $(n=9,8 \%)$. Causes of late mortality for 5 patients who did not undergo contrast-enhanced CT were pneumonia $(\mathrm{n}=3)$, malignancy $(\mathrm{n}=1)$, and sepsis $(\mathrm{n}=1)$. The causes of late mortality were assessed in relation to $\mathrm{FL}$ status for the remaining 110 patients (Table E1). Patients with a thrombosed FL were more likely than others to die of heart failure. Seventeen $(94 \%)$ of the 


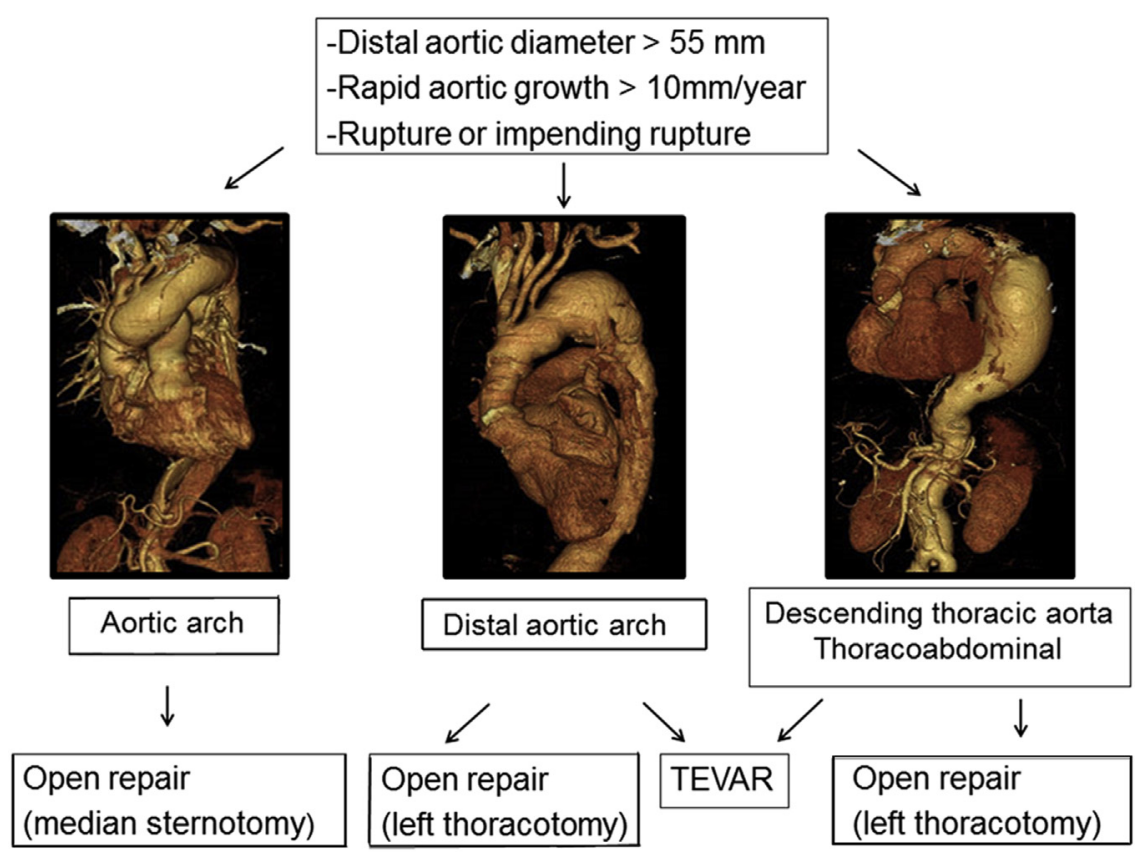

FIGURE 1. Treatment strategy for enlargement of the downstream aorta after the initial surgery for ATAAD. TEVAR, Thoracic endovascular aortic repair.

18 patients who died of aortic rupture or sudden death had a patent FL. Ten of the 18 patients had undergone CT within 1 year of death (Table E2). The median diameter of the aorta, per final measurement before rupture, was $55 \mathrm{~mm}$ (range, 50-67 mm). Four patients had a distal aorta exceeding $60 \mathrm{~mm}$ in diameter (patients 5-7 and 9); however, reoperation was not performed in these patients because of advanced age, frailty, or death before elective surgery. The remaining 6 patients had an aortic diameter ranging from 50 to $56 \mathrm{~mm}$, but only 1 patient showed rapid aortic growth more than $10 \mathrm{~mm} / \mathrm{year}$. The results of Cox proportional hazards modeling for long-term outcomes are shown in Table 2. Sixty-two distal aortic events, including 2 sudden deaths, 16 aortic ruptures, 1 re-dissection without surgical intervention, and 43 distal reoperations, occurred in 55

TABLE 2. Results of Cox proportional hazards analysis for predictors of survival and distal aortic events

\begin{tabular}{lrrr}
\hline \multicolumn{1}{c}{ Variable } & \multicolumn{3}{c}{ Hazard } \\
& $\boldsymbol{P}$ value & ratio & $\mathbf{9 5 \%} \mathbf{C I}$ \\
\hline Survival & & & \\
$\quad$ Age & $<.001$ & 1.07 & $1.04-1.09$ \\
$\quad$ Sex, male & .002 & 1.89 & $1.27-2.83$ \\
$\quad$ Patent FL & .011 & 1.71 & $1.12-2.59$ \\
Distal aortic events & & & \\
$\quad$ Marfan syndrome & $<.001$ & 6.60 & $2.69-16.22$ \\
$\quad$ Distal aortic diameter $>45 \mathrm{~mm}$ & $<.001$ & 4.37 & $2.51-7.62$ \\
$\quad$ Patent FL & .001 & 4.11 & $1.85-9.18$ \\
$\quad$ Nonresection of the primary entry & .005 & 2.26 & $1.27-4.01$ \\
\hline
\end{tabular}

$C I$, Confidence interval; $F L$, false lumen. patients. The risk-adjusted survival curve and distal aortic event-free curve are shown in Figure 2. A patent FL was identified as a risk factor for both death (hazard ratio [HR], 1.70; $P=.012)$ and distal aortic events (HR, 4.11; $P=.001)$.

\section{Distal Reoperation for an Enlarged Aorta}

Forty-three distal reoperations were performed in 37 patients, including 5 patients with Marfan syndrome. FL patency in this group was $92 \%$ (34/37). Four patients underwent staged aortic repair, including 2 distal reoperations $(\mathrm{n}=2)$ and 3 distal reoperations $(\mathrm{n}=2)$. The mean time between the initial aortic repair and the first distal reoperation was $5.6 \pm 3.9$ years. Thirty-six open distal reoperations were performed in 32 patients. The indications were chronic dissection with aneurysmal enlargement $(\mathrm{n}=30)$ and nondissecting thoracic aortic aneurysm $(\mathrm{n}=2)$. The median preoperative aneurysm diameter was $58 \mathrm{~mm}$ (range, 48-75 $\mathrm{mm}$ ). The intraoperative details of open distal reoperation are shown in Table 3. Aortic arch replacement was performed in 13 patients. Descending thoracic aorta and thoracoabdominal aorta replacement were performed in 16 patients and 7 patients, respectively. Four patients, 2 with a limited thoracic aneurysm and 2 who had undergone aortic arch replacement by the elephant trunk procedure, were treated with partial CPB and mild hypothermia. All 7 patients who underwent thoracoabdominal aorta replacement underwent intercostal artery reconstruction (separately, $\mathrm{n}=4$; island technique, $\mathrm{n}=3$ ) and visceral and renal artery reconstruction (separately, $\mathrm{n}=6$; island technique, $\mathrm{n}=1$ ). 

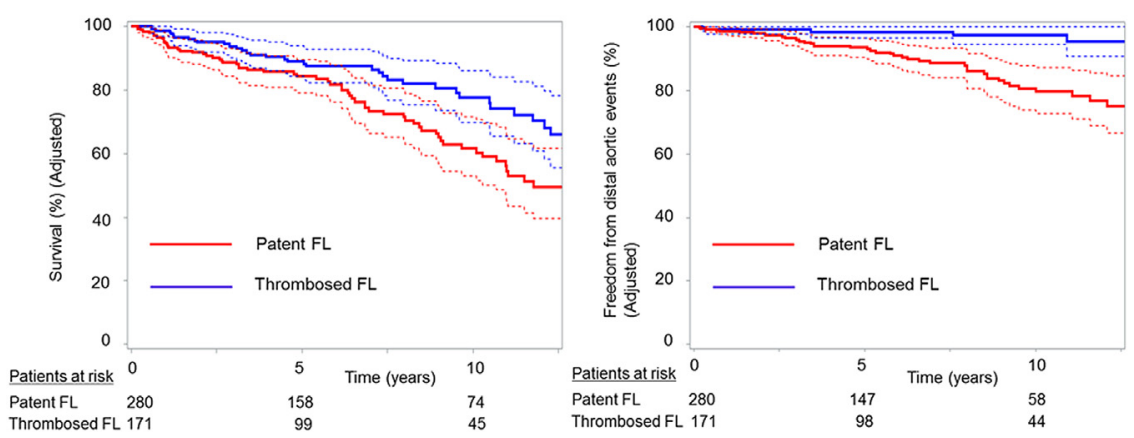

FIGURE 2. Risk-adjusted survival of patients with a patent versus thrombosed FL (left) and risk-adjusted freedom from distal aortic events for patients with a patent versus thrombosed FL (right). Dot plots indicate 95\% confidence interval. FL, False lumen.

Seven patients underwent TEVAR for enlargement of the downstream aorta during follow-up. These cases involved chronic dissection with aneurysmal enlargement $(\mathrm{n}=5)$ and nondissecting thoracic aortic aneurysm

TABLE 3. Perioperative details of open distal reoperations $(n=36)$

\begin{tabular}{|c|c|}
\hline Variables & \\
\hline Emergency surgery & $5(12 \%)$ \\
\hline Aortic arch replacement & Total, $\mathrm{n}=13$ \\
\hline Total arch replacement & $11(85 \%)$ \\
\hline $\begin{array}{l}\text { Partial arch replacement (reconstruction of } 1 \text { or } \\
2 \text { branches) }\end{array}$ & $2(15 \%)$ \\
\hline Elephant trunk & $6(46 \%)$ \\
\hline Proximal descending thoracic aorta replacement & $3(23 \%)$ \\
\hline $\mathrm{CPB}$ time, mean $\pm \mathrm{SD}(\min )$ & $194 \pm 47$ \\
\hline Myocardial ischemia time, mean $\pm \mathrm{SD}(\min )$ & $106 \pm 33$ \\
\hline $\mathrm{HCA}$ time, mean $\pm \mathrm{SD}(\mathrm{min})$ & $64 \pm 28$ \\
\hline Selective cerebral perfusion time, mean $\pm \mathrm{SD}$ (min) & $129 \pm 38$ \\
\hline Lowest temperature, mean $\pm \mathrm{SD}\left({ }^{\circ} \mathrm{C}\right)$ & $20.4 \pm 1.6$ \\
\hline Concomitant procedure, tricuspid valve annuloplasty & $1(8 \%)$ \\
\hline $\begin{array}{l}\text { Descending thoracic aorta and thoracoabdominal } \\
\text { replacement }\end{array}$ & Total, $\mathrm{n}=23$ \\
\hline \multicolumn{2}{|l|}{ Location of the enlargement } \\
\hline Descending thoracic aorta & $16(69 \%)$ \\
\hline Proximal/middle & $8(35 \%)$ \\
\hline Middle/distal & $2(9 \%)$ \\
\hline Proximal/middle/distal & $6(26 \%)$ \\
\hline Thoracoabdominal aorta & $7(30 \%)$ \\
\hline Extent II & $3(13 \%)$ \\
\hline Extent III & $3(13 \%)$ \\
\hline Extent IV & $1(4 \%)$ \\
\hline Prior aortic arch replacement with elephant trunk & $2(9 \%)$ \\
\hline Cerebrospinal fluid drainage & $7(30 \%)$ \\
\hline Intercostal artery reconstruction & $7(30 \%)$ \\
\hline Visceral and renal artery reconstruction & $7(30 \%)$ \\
\hline Partial CPB & $4(17 \%)$ \\
\hline $\mathrm{CPB}$ time, mean $\pm \mathrm{SD}(\min )$ & $183 \pm 56$ \\
\hline HCA time, ${ }^{*}$ mean $\pm \mathrm{SD}(\min )$ & $60 \pm 27$ \\
\hline Lowest temperature, ${ }^{*}$ mean $\pm \mathrm{SD}\left({ }^{\circ} \mathrm{C}\right)$ & $20.3 \pm 2.3$ \\
\hline
\end{tabular}

Number and percentage of patients are shown unless otherwise indicated. $C P B$, Cardiopulmonary bypass, $H C A$, hypothermic circulatory arrest; $S D$, standard deviation. *Analyzed for patients who underwent HCA. $(\mathrm{n}=2)$. The median preoperative aneurysm diameter was $54 \mathrm{~mm}$ (range, $45-57 \mathrm{~mm}$ ). The median length of aorta covered by the stent-graft was $195 \mathrm{~mm}$ (range, 150-230 $\mathrm{mm}$ ). The perioperative details of TEVAR are summarized in Table 4. TEVAR was successfully performed in all $7 \mathrm{pa}-$ tients. Of the 4 patients with a distal arch aneurysm, 3 underwent TEVAR with a Najuta stent graft, and 1 underwent TEVAR with a Relay stent graft. The proximal landing zone in these patients ranged from zone 0 (graft) to zone 2. Mild type Ia endoleak occurred in 1 patient with a Najuta graft.

There was no 30-day death, in-hospital death, stroke, or spinal cord ischemia after the distal reoperations. Mean stay in the intensive care unit was $7.7 \pm 9.8$ days (range, 3-57 days) for patients treated with an open reoperation and $2.6 \pm 1.1$ days (range, 2-5 days) for patients treated with TEVAR. Major complications after open repair included a need for ventilation more than 48 hours $(\mathrm{n}=12)$, pneumonia $(\mathrm{n}=3)$, tracheostomy $(\mathrm{n}=2)$, seizure without irreversible brain damage $(\mathrm{n}=2)$, and bleeding requiring reexploration $(\mathrm{n}=1)$. Only 1 patient who underwent TEVAR showed bleeding from the iliac conduit. Postoperative CT within 6 months of the procedure showed no migration of the stent-graft. Of the 5 patients with chronic dissection, TEVAR resulted in FL thrombosis at the level of the stent graft in 4 patients $(80 \%)$, and the maximum diameter of the thoracic aorta did not increase significantly (from 56.7 $\pm 6.3 \mathrm{~mm}$ to $52.6 \pm 9.5, P=.44)$ and neither did the maximum diameter of the abdominal aorta (from 30.8 \pm 7.4 to $30.2 \pm 7.0, P=.89$ ). However, complete FL thrombosis of the entire thoracic and abdominal aorta was seen in only 1 of the 5 patients $(20 \%)$ (Figure 3 ). No patient required a secondary procedure after TEVAR during follow-up (mean follow-up period, $15.3 \pm 9.4$ months).

\section{DISCUSSION}

In the present study, we assessed late outcomes according to FL status for a total of 452 patients who underwent 
TABLE 4. Perioperative details of endovascular distal reoperation $(\mathbf{n}=7)$

\begin{tabular}{lc}
\hline \multicolumn{1}{c}{ Variable } \\
\hline Emergency surgery & $2(28 \%)$ \\
Location of the enlargement & \\
$\quad$ Distal aortic arch/proximal descending thoracic aorta & $5(71 \%)$ \\
$\quad$ Proximal/middle descending thoracic aorta & $2(29 \%)$ \\
Stent graft type & \\
$\quad$ Najuta (Kawasumi Laboratory, Tokyo, Japan) & $3(57 \%)$ \\
Zenith Tx2 (Cook Medical Inc, Bloomington, Ind) & $2(28 \%)$ \\
$\quad$ Relay (Bolton Medical SL, Barcelona, Spain) & $1(14 \%)$ \\
$\quad$ GORE TAG (WL Gore \& Associates, Inc, Flagstaff, Ariz) & $1(14 \%)$ \\
Prior distal aortic reoperation & $1(14 \%)$ \\
Cerebrospinal fluid drainage & $2(28 \%)$ \\
Access & \\
$\quad$ Femoral artery & $6(86 \%)$ \\
Common iliac artery & $1(14 \%)$ \\
Proximal landing zone & \\
$\quad$ Zone 0 & $1(14 \%)$ \\
Zone 1 & $2(28 \%)$ \\
Zone 2 & $1(14 \%)$ \\
Zone 4-Th5 & $3(42 \%)$ \\
Left subclavian artery & \\
Preserved in the fenestration & $1(14 \%)$ \\
Occluded & $1(14 \%)$ \\
Revascularization & $2(28 \%)$ \\
$\quad$ Debranching with left carotid-subclavian bypass & $1(14 \%)$ \\
Chimney-stent graft & $1(14 \%)$ \\
Type Ia (antegrade perfusion to the FL) & \\
Operation time, mean \pm SD (min) & $1(14 \%)$ \\
Contrast volume, mean \pm SD (mL) & $236 \pm 110$ \\
Number and percentage of patients are shown unless otherwise indicated. FL, False \\
lumen; SD, standard deviation.
\end{tabular}

emergency surgery for ATAAD. As far as we know, our study is the largest single-center study to investigate the influence of a patent FL on late outcomes of ATAAD repair. A residual patent FL has been reported as a predictor for late enlargement of the distal aorta. ${ }^{7,9-13}$ We previously reported no significant difference in survival between patients with and without a patent FL after surgery for ATAAD; however, our finding was based on nonrisk-adjusted log-rank analysis. ${ }^{15}$ Although a similar finding of no difference in late survival by log-rank analysis was obtained in the present study (data not shown), we showed, by means of multivariate analysis using Cox proportional hazard modeling, FL patency in the downstream aorta to be a predictor of both late mortality and distal aortic events. When aortic arch replacement is performed in selected patients, the reported FL patency of the downstream aorta is generally high, ranging from $43 \%$ to $77.5 \%,{ }^{7,8,13,20}$ and the patency we observed was in keeping with these reported percentages. Although approximately $50 \%$ of patients with a patent FL show slow aortic growth $(<1 \mathrm{~mm} / \mathrm{y}),{ }^{15}$ when there is a tendency toward expansion, the patent FL steadily induces enlargement of the downstream aorta, leading to distal aortic events.

Some groups recently have reported that total arch or hemiarch replacement combined with the FET procedure provides excellent late outcomes and low FL patency without increasing in-hospital mortality and morbidity. ${ }^{1-4}$ Although spinal cord ischemia is one of the most serious complications associated with FET, its incidence is low, ranging from $1.4 \%$ to $2.0 \%{ }^{1,3}$ Therefore, if nonelderly patients are preoperatively stable, we consider such extended hybrid procedures to be the preferable surgical approach to prevent late aortic events. Gariboldi and colleagues ${ }^{20}$ investigated predictors of FL thrombosis after repair for ATAAD. They performed aortic arch replacement in $12 \%$ of patients with ATAAD, and age more than 70 years and valve-sparing root reconstruction were identified as predictors of FL thrombosis. ${ }^{20}$ We observed a similar trend, that is, our patients with a thrombosed FL were older than our patients with a patent FL. In addition, surgical risk is greater in elderly patients than in nonelderly patients. ${ }^{21}$ We believe ascending aorta or hemiarch replacement should remain the standard therapy for elderly patients in the era of FET.

Eighteen of our patients died of aortic rupture or sudden death during follow-up. The best time to perform distal reoperation in asymptomatic patients remains a difficult question. Previously, we adopted $60 \mathrm{~mm}$ as a cutoff criterion for distal aortic reoperation, similar to the criterion in patients with thoracic aortic aneurysm. ${ }^{15}$ Now, we use 55 $\mathrm{mm}$ as a cutoff, as the expert consensus report recommended. ${ }^{22}$ However, most of our patients who died of aortic rupture showed a patent FL without rapid aortic growth, and the median diameter before rupture was $56 \mathrm{~mm}$. Our findings are consistent with those of Crawford, ${ }^{23}$ who reported that in $23 \%$ of patients presenting with rupture of a chronically dissected descending aorta, the aorta ranged in size from 50 to $60 \mathrm{~mm} .^{23}$ Therefore, if there is an obvious tendency toward expansion in young and healthy patients, reoperation should be considered for an aortic diameter of $50 \mathrm{~mm}$ or more.

The outcomes of distal reoperation in our patient series were acceptable, and there were no in-hospital deaths resulting from the 43 reoperations, including 7 performed for aortic rupture or impending rupture. We performed endovascular treatment in 7 patients, including 2 with rupture. Compared with conventional open surgical treatment, TEVAR is less invasive and associated with fewer postoperative complications, leading to a shortened hospital stay. However, controversy exists over whether TEVAR is indicated for chronic dissection with aneurysmal enlargement. ${ }^{22,24,25} \mathrm{~A}$ rigid dissection flap and multiple fenestrations between the true lumen and FL are thought to inhibit the aortic remodeling associated with TEVAR for chronic type B dissection. ${ }^{22}$ In addition, TEVAR for 


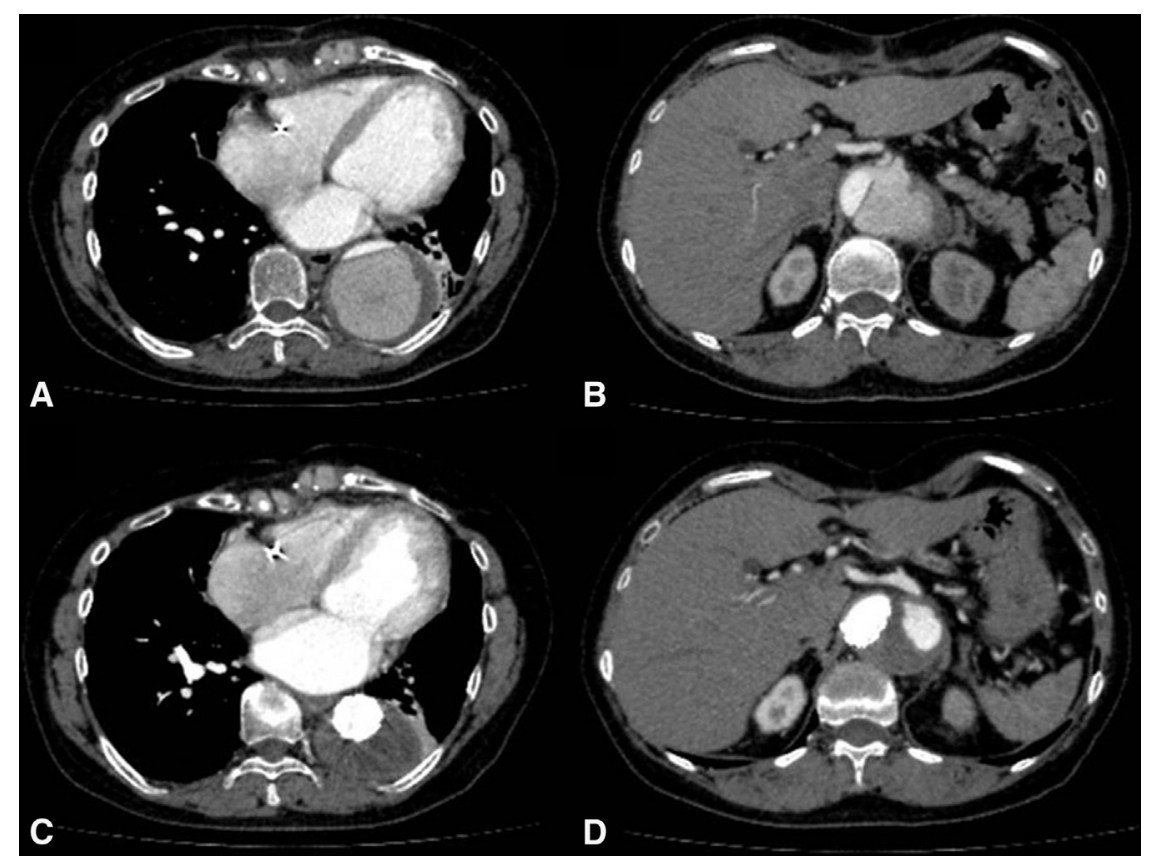

FIGURE 3. Representative CT images of chronic dissection after TEVAR. Preoperative images of the thoracic (A) and abdominal (B) aorta, and postoperative (15 months) images of the thoracic (C) and abdominal (D) aorta. Although thrombosis of the FL and decreased total aorta size are confirmed in the thoracic descending aorta, the FL is patent in the abdominal aorta.

aortic arch enlargement after type A repair is challenging, despite the fact that it is technically possible with arch vessel debranching or the chimney technique. Therefore, we believe open surgical treatment should remain the first-line therapy for chronic dissection with aneurysmal enlargement after type A repair, especially in patients who are not elderly or at low operative risk. However, in cases of distal aortic arch or descending thoracic aorta enlargement, TEVAR might be an alternative therapy for elderly or frail patients. TEVAR for chronic dissection after type A repair is technically similar to TEVAR for chronic type B dissection in some respects. Both procedures require coverage of the primary entry tear and aortic arch debranching when a nonfenestrated stent graft covers the left subclavian artery. However, there are some differences between these 2 situations. Tortuosity and crimping of the transplanted graft sometimes complicate delivery of the sheath. In addition, size mismatch between the proximal graft and the distal aneurysmal enlargement is sometimes more pronounced than size mismatch found in chronic type B dissection. Although there is no risk of retrograde dissection, TEVAR for chronic dissection after type A repair may require delicate surgical techniques. TEVAR is reported to decrease the aortic diameter and promote FL thrombosis around the stent-graft in patients with chronic type B dissection, ${ }^{25,26}$ and we confirmed this phenomenon. Although complete FL thrombosis has been reported to foster aortic remodeling, ${ }^{27}$ only 1 of our patients showed complete thrombosis after TEVAR. The effect of a partial patent FL on late outcomes after TEVAR is not fully understood. Long-term follow-up study is needed to clarify the influence of partial thrombosis.

\section{Study Limitations}

First, it was a retrospective study conducted to analyze the surgical outcomes of initial repair for ATAAD over a 20 -year period. Diagnostic imaging systems, surgical techniques, and postoperative care have changed during this period. Second, we focused on distal reoperations to assess the influence of FL patency, and as a result, we analyzed fewer cases of reoperation than were reported in a previous study. ${ }^{28}$ Any one hospital's surgical volume for aortic disease is limited; thus, a large-scale multicenter study is needed for a full understanding of the influence of FL patency on outcomes of ATAAD repair.

\section{CONCLUSIONS}

Postoperative FL patency was 62\% (280/451) in our patient series. Cox proportional hazards modeling showed a patent FL to be a predictor of both late mortality and distal aortic events. The other identified predictors for distal aortic events include Marfan syndrome, distal aortic diameter greater than $45 \mathrm{~mm}$, and nonresection of the primary entry site. Careful follow-up is important for patients with these predictive factors. A total of 43 distal reoperations were performed during follow-up, including 36 open repairs and 7 TEVARs, with no in-hospital death or paraplegia. Thus, timely additional reoperation may improve late 
outcomes. TEVAR yielded FL thrombosis and decreased the aortic diameter in $80 \%$ of patients with chronic dissection; however, complete FL thrombosis throughout the thoracic and abdominal aorta was achieved in $20 \%$. Whether TEVAR is indicated for patients with chronic dissection and aneurysmal enlargement should be carefully determined on the basis of aortic pathology and patient status.

The authors thank Dr Makiko Mieno (Medical Information Center, Jichi Medical University) for useful discussion.

\section{References}

1. Ius F, Hagl C, Haverich A, Pichlmaier M. Elephant trunk procedure 27 years after Borst: what remains and what is new? Eur J Cardiothorac Surg. 2011;40:1-11.

2. Uchida N, Katayama A, Tamura K, Sutoh M, Kuraoka M, Ishihara H Frozen elephant trunk technique and partial remodeling for acute type A aortic dissection. Eur J Cardiothorac Surg. 2011;40:1066-71.

3. Sun L, Qi R, Zhu J, Liu Y, Zheng J. Total arch replacement combined with stented elephant trunk implantation: a new "standard" therapy for type A dissection involving repair of the aortic arch? Circulation. 2011;123:971-8.

4. Shi E, Gu T, Yu Y, Yu L, Wang C, Fang Q, et al. Early and midterm outcomes of hemiarch replacement combined with stented elephant trunk in the management of acute DeBakey type I aortic dissection: comparison with total arch replacement. J Thorac Cardiovasc Surg. November 28, 2013 [Epub ahead of print].

5. Wu HB, Zhang H, Wang ZW, Hu R, Li LC, Zhang M, et al. Surgery for acute aortic dissection using the Chinese CRONUS stented elephant trunk technique: experience with 252 patients. J Thorac Cardiovasc Surg. January 2, 2014 [Epub ahead of print].

6. Conzelmann LO, Hoffmann I, Blettner M, Kallenbach K, Karck M, Dapunt O, et al. Analysis of risk factors for neurological dysfunction in patients with acute aortic dissection type A: data from the German Registry for Acute Aortic Dissection Type A (GERAADA). Eur J Cardiothorac Surg. 2012;42:557-65.

7. Halstead JC, Meier M, Etz C, Spielvogel D, Bodian C, Wurm M, et al. The fate of the distal aorta after repair of acute type A aortic dissection. J Thorac Cardiovasc Surg. 2007; 133:127-35

8. Fattori R, Bacchi-Reggiani L, Bertaccini P, Napoli G, Fusco F, Longo M, et al. Evolution of aortic dissection after surgical repair. Am J Cardiol. 2000;86: 868-72.

9. Yeh $\mathrm{CH}$, Chen $\mathrm{MC}$, Wu YC, Wang YC, Chu JJ, Lin PJ. Risk factors for descending aortic aneurysm formation in medium-term follow-up of patients with type A aortic dissection. Chest. 2003;124:989-95.

10. Zierer A, Voeller RK, Hill KE, Kouchoukos NT, Damiano RJ Jr, Moon MR. Aortic enlargement and late reoperation after repair of acute type A aortic dissection. Ann Thorac Surg. 2007;84:479-87.

11. Concistre G, Casali G, Santaniello E, Montalto A, Fiorani B, Dell'Aquila A, et al. Reoperation after surgical correction of acute type A aortic dissection: risk factor analysis. Ann Thorac Surg. 2012;93:450-5.

12. Fattouch K, Sampognaro R, Navarra E, Caruso M, Pisano C, Coppola G, et al. Long-term results after repair of type A acute aortic dissection according to false lumen patency. Ann Thorac Surg. 2009;88:1244-50.
13. Park KH, Lim C, Choi JH, Chung E, Choi SI, Chun EJ, et al. Midterm change of descending aortic false lumen after repair of acute type I dissection. Ann Thorac Surg. 2009;87:103-8.

14. Tsai MT, Wu HY, Roan JN, Tsai YS, Hsieh PC, Yang YJ, et al. Effect of false lumen partial thrombosis on repaired acute type A aortic dissection. J Thorac Cardiovasc Surg. February 12, 2014 [Epub ahead of print].

15. Kimura N, Tanaka M, Kawahito K, Yamaguchi A, Ino T, Adachi $H$. Influence of patent false lumen on long-term outcome after surgery for acute type A aortic dissection. J Thorac Cardiovasc Surg. 2008;136:1160-6, 1166. e1161-3.

16. Kimura N, Ohnuma T, Itoh S, Sasabuchi Y, Asaka K, Shiotsuka J, et al. Utility of the Penn classification in predicting outcomes of surgery for acute type A aortic dissection. Am J Cardiol. 2014;113:724-30.

17. Yuri K, Yokoi Y, Yamaguchi A, Hori D, Adachi K, Adachi H. Usefulness of fenestrated stent grafts for thoracic aortic aneurysms. Eur J Cardiothorac Surg. 2013;44:760-7.

18. Yokoi Y, Azuma T, Yamazaki K. Advantage of a precurved fenestrated endograft for aortic arch disease: simplified arch aneurysm treatment in Japan 2010 and 2011. J Thorac Cardiovasc Surg. 2013;145:S103-9.

19. Grabenwoger M, Alfonso F, Bachet J, Bonser R, Czerny M, Eggebrecht H, et al. Thoracic endovascular aortic repair (TEVAR) for the treatment of aortic diseases: a position statement from the European Association for Cardio-Thoracic Surgery (EACTS) and the European Society of Cardiology (ESC), in collaboration with the European Association of Percutaneous Cardiovascular Interventions (EAPCI). Eur J Cardiothorac Surg. 2012;42:17-24.

20. Gariboldi V, Grisoli D, Kerbaul F, Giorgi R, Riberi A, Metras D, et al. Long-term outcomes after repaired acute type A aortic dissections. Interact Cardiovasc Thorac Surg. 2007;6:47-51.

21. Trimarchi S, Eagle KA, Nienaber CA, Rampoldi V, Jonker FH, De Vincentiis C, et al. Role of age in acute type A aortic dissection outcome: report from the International Registry of Acute Aortic Dissection (IRAD). J Thorac Cardiovasc Surg. 2010;140:784-9.

22. Svensson LG, Kouchoukos NT, Miller DC, Bavaria JE, Coselli JS, Curi MA, et al. Expert consensus document on the treatment of descending thoracic aortic disease using endovascular stent-grafts. Ann Thorac Surg. 2008;85: S1-41.

23. Crawford ES. The diagnosis and management of aortic dissection. JAMA. 1990; 264:2537-41.

24. Thrumurthy SG, Karthikesalingam A, Patterson BO, Holt PJ, Hinchliffe RJ, Loftus IM, et al. A systematic review of mid-term outcomes of thoracic endovascular repair (TEVAR) of chronic type B aortic dissection. Eur J Vasc Endovasc Surg. 2011;42:632-47.

25. Scali ST, Feezor RJ, Chang CK, Stone DH, Hess PJ, Martin TD, et al. Efficacy of thoracic endovascular stent repair for chronic type B aortic dissection with aneurysmal degeneration. J Vasc Surg. 2013;58:10-7.e11.

26. Kang WC, Greenberg RK, Mastracci TM, Eagleton MJ, Hernandez AV, Pujara AC, et al. Endovascular repair of complicated chronic distal aortic dissections: intermediate outcomes and complications. J Thorac Cardiovasc Surg. 2011;142:1074-83.

27. Trimarchi S, Tolenaar JL, Jonker FH, Murray B, Tsai TT, Eagle KA, et al. Importance of false lumen thrombosis in type B aortic dissection prognosis. J Thorac Cardiovasc Surg. 2013;145:S208-12.

28. Malvindi PG, van Putte BP, Sonker U, Heijmen RH, Schepens MA, Morshuis WJ. Reoperation after acute type A aortic dissection repair: a series of 104 patients. Ann Thorac Surg. 2013;95:922-7. 
TABLE E1. Causes of late mortality per false lumen status

\begin{tabular}{lccr}
\hline & $\begin{array}{c}\text { Patent FL } \\
(\mathbf{n}=\mathbf{6 7})\end{array}$ & $\begin{array}{c}\text { Thrombosed } \\
\text { FL }(\mathbf{n}=\mathbf{4 3})\end{array}$ & $\begin{array}{c}\boldsymbol{P} \\
\text { value }\end{array}$ \\
\hline Malignancy & $15(22 \%)$ & $10(23 \%)$ & .92 \\
Heart failure & $10(15 \%)$ & $14(33 \%)$ & .03 \\
Aortic rupture or sudden death & $17(25 \%)$ & $1(2 \%)$ & $<.01$ \\
Cerebrovascular disease & $10(15 \%)$ & $5(12 \%)$ & .78 \\
Pneumonia & $9(13 \%)$ & $5(12 \%)$ & .62 \\
Renal failure & $2(3 \%)$ & $4(9 \%)$ & .16 \\
Other & $4(6 \%)$ & $4(9 \%)$ & .51 \\
\hline
\end{tabular}

Number and percentage of patients are shown. $F L$, False lumen.

TABLE E2. Characteristics of patients who died of late thoracic aorta rupture

\begin{tabular}{|c|c|c|c|c|c|c|c|c|}
\hline Patient & Age*/sex & Diagnosis & $\begin{array}{c}\text { Marfan } \\
\text { syndrome }\end{array}$ & Patent FL & $\begin{array}{c}\text { Aortic } \\
\text { diameter at } \\
\text { discharge }(\mathbf{m m}) \\
\end{array}$ & $\begin{array}{c}\text { Aortic diameter } \\
\text { within } 1 \text { y of } \\
\text { death }(\mathbf{m m})\end{array}$ & $\begin{array}{c}\text { Rapid aortic } \\
\text { growth } \\
(>10 \mathrm{~mm} / \mathrm{y}) \\
\end{array}$ & $\begin{array}{c}\text { Time from } \\
\text { initial surgery } \\
\text { to death }(y)\end{array}$ \\
\hline 1 & $39 \mathrm{y} / \mathrm{M}$ & Rupture & No & Patent & 44 & 56 & No & 2.6 \\
\hline 2 & $41 \mathrm{y} / \mathrm{M}$ & Rupture & Yes & Patent & 40 & 50 & No & 14.8 \\
\hline 3 & $52 \mathrm{y} / \mathrm{M}$ & Rupture & No & Patent & 35 & 53 & Yes & 8.7 \\
\hline 4 & $54 \mathrm{y} / \mathrm{F}$ & Rupture & No & Patent & 47 & 55 & No & 2.6 \\
\hline 5 & $61 \mathrm{y} / \mathrm{M}$ & Rupture & No & Patent & 67 & 67 & No & 0.2 \\
\hline 6 & $65 \mathrm{y} / \mathrm{M}$ & Rupture & No & Patent & 46 & 65 & No & 9.1 \\
\hline 7 & $67 \mathrm{y} / \mathrm{F}$ & Rupture & No & Patent & 46 & 61 & No & 7.9 \\
\hline 8 & $69 \mathrm{y} / \mathrm{F}$ & Rupture & No & Patent & 44 & 50 & No & 1.0 \\
\hline 9 & $69 \mathrm{y} / \mathrm{M}$ & Rupture & No & Patent & 50 & 64 & No & 3.1 \\
\hline 10 & $75 \mathrm{y} / \mathrm{F}$ & Sudden death & No & Patent & 52 & 55 & No & 2.1 \\
\hline
\end{tabular}

$F L$, False lumen. *Age at the time of initial surgery. 